\title{
Predação de Columbina squammata Lesson, 1831 (Aves: Columbidae) por Cariama cristata Linnaeus, 1766 (Aves: Cariamidae) \\ Predation of Columbina squammata Lesson, 1831 (Aves: Columbidae) by Cariama cristata Linnaeus, 1766 (Aves: Cariamidae)
}

\author{
Sandro Gonçalves Moreira \\ Pesquisador independente. Uberlândia, Minas Gerais, Brasil
}

Resumo: $O$ presente trabalho relata o primeiro registro de predação de fogo-apagou (Columbina squammata Lesson, 1831) por seriema (Cariama cristata Linnaeus, 1766), na zona rural do município de Uberlândia, Minas Gerais, Brasil.

Palavras-chave: Seriema. Fogo-apagou. Relações ecológicas.

Abstract: The present paper reports the first record of predation of the scaled dove (Columbina squammata Lesson, 1831) by red-legged seriema (Cariama cristata Linnaeus, 1766), in the countryside of the municipality of Uberlândia, Minas Gerais, Brazil.

Keywords: Red-legged seriema. Scaled dove. Ecological relations.

MOREIRA, S. G., 2017. Predação de Columbina squammata Lesson, 1831 (Aves: Columbidae) por Cariama cristata Linnaeus, 1766 (Aves: Cariamidae). Boletim do Museu Paraense Emílio Goeldi. Ciências Naturais 12(1): 137-140.

Autor para correspondência: Sandro Gonçalves Moreira. Rua José Maria Malva, 38 - Nova Uberlândia. Uberlândia, MG, Brasil. CEP 38412-630 (sandroechoavis@hotmail.com).

Recebido em 21/06/2017

Aprovado em 26/08/2017

Responsabilidade editorial: Fernando da Silva Carvalho Filho

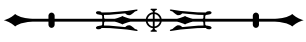


Columbina squammata Lesson, 1831, popularmente conhecida como fogo-apagou, rolinha-carijó, rola-pedrês, paruru, galinha-de-deus ou rola cascavel, é um columbídeo comumente encontrado em praticamente todo o Brasil, desde ambientes preservados a altamente antropizados (Wikiaves, 2017). Espécie granívora, com cerca de 20 centímetros de comprimento, facilmente reconhecida pelo canto onomatopeico característico ("ú gu-gú"), por possuir cauda com retrizes externas mais longas, com laterais brancas, bem como por apresentar plumagem escamosa clara, barrada de preto (Sick, 1997). Apesar de empiricamente se saber que se trata de uma espécie que faz parte da dieta de muitos predadores, há poucos registros disponíveis na literatura sobre tal interação (Miranda et al., 2013).

A seriema (Cariama cristata Linnaeus, 1766) é endêmica da América do Sul, sendo uma das duas únicas espécies vivas da família Cariamidae. Possui de 75 a $90 \mathrm{~cm}$ de comprimento e pesa cerca de $1,5 \mathrm{~kg}$ (Gonzaga \& Kirwan, 2017). A plumagem nas aves adultas possui coloração acinzentada, com tonalidade levemente parda ou amarelada; o bico, assim como os tarsos, é vermelho e de sua base cresce um feixe de penas eriçadas (Sick, 1997), característica exclusiva entre as aves sul-americanas (Hallager, 2013). A região perioftálmica possui coloração em tons de azul, e a íris é amarela. Possui discreto dimorfismo sexual, sendo que o macho possui penas da crista maiores, com tamanho ligeiramente maior do que o da fêmea (AZA, 2013; Hallager, 2013).

Esta espécie ocorre tipicamente em regiões campestres, principalmente em áreas de cerrado, de campos sujos e de planaltos no sudeste do Brasil, no Paraguai, no Uruguai, na Bolívia e na Argentina (Hallager, 2013). No entanto, ela vem ocupando outras regiões, em decorrência do desmatamento progressivo de áreas florestais, que lhe cria hábitat favorável, em razão do aumento das regiões de campo aberto (AZA, 2013; Sick, 1997), sendo observada inclusive em propriedades rurais (Gonzaga \& Kirwan, 2017).
Normalmente, esta espécie forrageia solitariamente ou aos pares, podendo eventualmente formar pequenos grupos familiares. Ela também se desloca lentamente à procura de presas no solo, ou permanece camuflada na vegetação baixa, à espreita das mesmas (Gonzaga \& Kirwan, 2017).

Possui hábito alimentar onívoro/insetívoro, incluindo itens vegetais, como grãos, sementes, frutos silvestres e gomas, e também animais, como artrópodes, anelídeos, roedores e pequenos répteis, sendo que no período reprodutivo, momento em que o casal parental se mostra altamente territorialista, há prevalência para a captura de pequenos vertebrados com a finalidade de alimentar os filhotes (Almeida, 1994; Sick, 1997; AZA, 2013; Folly et al., 2015; Silva et al., 2016; Gonzaga \& Kirwan, 2017).

Embora seja uma ave muito comum em várias regiões da América do Sul, pouco tem sido publicado sobre esta espécie. A maioria das informações sobre seriemas está relacionada a espécimes de cativeiro (Brooks, 2014).

Ao dia 26 de junho de 2016, às 10:55 h, no condomínio de chácaras Eldorado, situado a $15 \mathrm{~km}$ do perímetro urbano de Uberlândia, em Minas Gerais, foram observadas, de maneira direta, e registradas em fotografia a captura e a predação de um indivíduo adulto da espécie Columbina squammata por uma seriema.

O indivíduo predado incubava os ovos em um ninho localizado sob o telhado de uma edificação (Figura 1A). A ave saiu do ninho, sobrevoou uma região gramada e pousou, provavelmente para forragear; após alguns segundos, foi capturada pela seriema, que estava forrageando sozinha no local, provavelmente capturando pequenos artrópodes.

A seriema aproximou-se lentamente por trás da fogo-apagou e, quando próxima, alinhou a cabeça com o corpo, esticou lentamente o pescoço, capturando-a, em seguida, com o bico em um movimento rápido, comportamento similar ao descrito por Silva et al. (2016). 

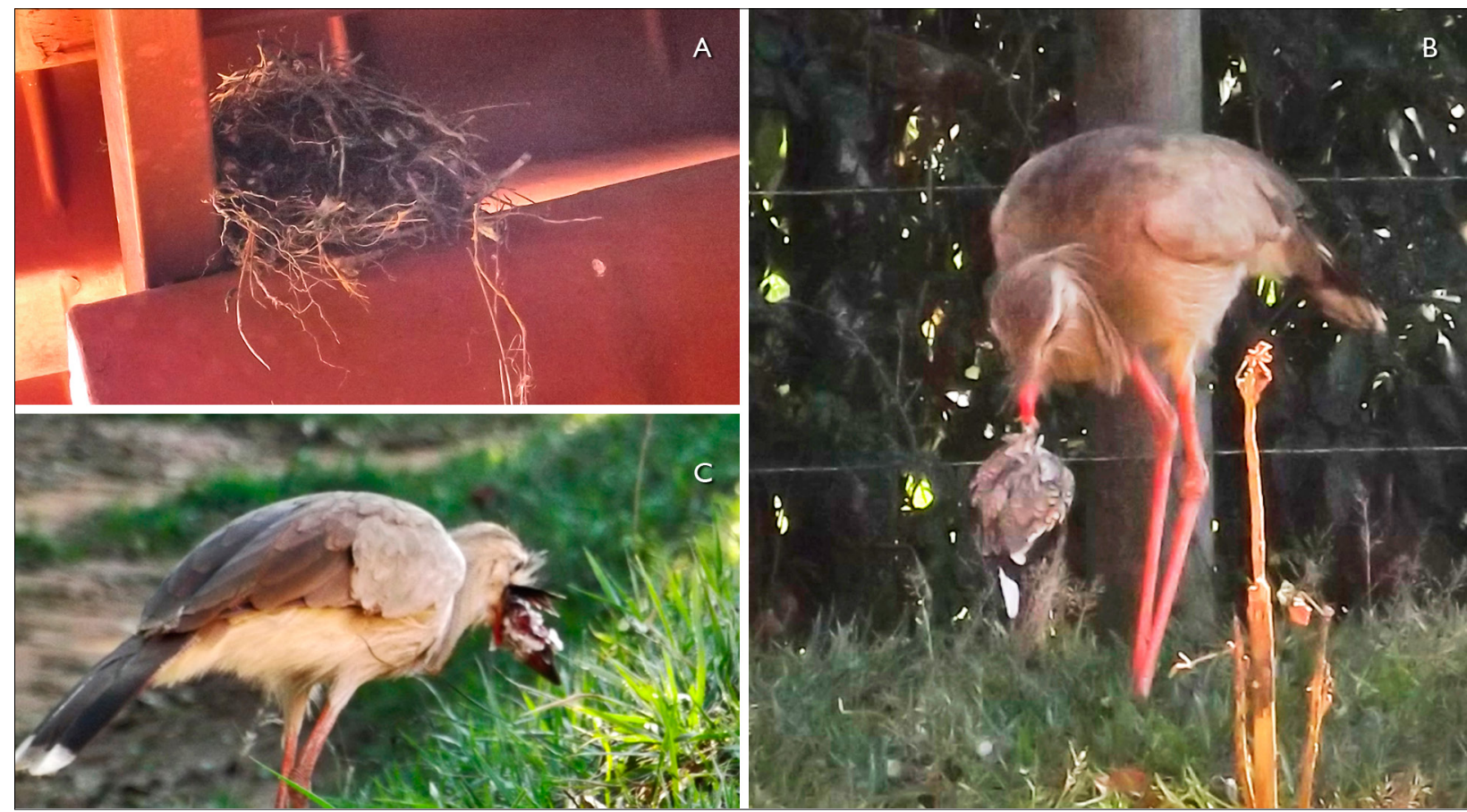

Figura 1. A) Ninho de Columbina squammata; B e C) Cariama cristata durante predação a Columbina squammata no condomínio de chácaras Eldorado, em Uberlândia, Minas Gerais. Fotos: Sandro Gonçalves Moreira, obtidas em junho de 2016.

Não foi possível notar a maneira como a presa foi morta, mas, provavelmente, não ocorreu da forma frequentemente relatada na literatura, em que ela é batida várias vezes contra o solo (Gonzaga \& Kirwan, 2017). Neste caso, a morte ocorreu de algum modo mais rápido, por bicadas na cabeça ou na região cervical, como observado por Cardoso \& Santos (2012). Após a captura, a seriema pisou sobre a presa e, com auxílio do bico, arrancou e ingeriu pequenos pedaços, inclusive com penas (Figura 1B), comportamento equivalente ao descrito por Gonzaga \& Kirwan (2017), a respeito da forma de manipulação da presa. Depois de cerca de 20 minutos após a captura, o restante da espécie predada (que representava quase toda a sua massa) foi ingerido, sendo a deglutição iniciada pela cabeça (Figura 1C), com movimentos verticais da cabeça da ave predadora, como observado por Silva et al. (2016), ao registrarem a ingestão de presas maiores (roedores e répteis) por C. cristata. $\bigcirc$ evento teve duração de aproximadamente 25 minutos.
A proximidade humana durante a atividade não pareceu interferir no evento relatado, como também observado por Cardoso \& Santos (2012), em seus relatos de predação da Philodryas patagoniensis por seriemas.

De acordo com Hallager (2013), C. cristata pode se alimentar de filhotes de aves se houver oportunidade, no entanto, a predação de espécies adultas é algo pouco relatado na literatura.

\section{REFERÊNCIAS}

ALMEIDA, A. C. C., 1994. Nota sobre biologia reprodutiva de seriema Cariama cristata (Linnaeus, 1766) (Gruiformes - Cariamidae). Revista Nordestina de Biologia 9(1): 49-59.

ASSOCIATION OF ZOOS AND AQUARIUMS (AZA), 2013. Redlegged seriema (Cariama cristata) care manual. Association of Zoos and Aquariums, Silver Spring. Disponível em: <https://www.aza.org/ assets/2332/red_legged_seriema_care_manual_2013.pdf $>$. Acesso em: 15 janeiro $\overline{2017 .}$

BROOKS, D. M., 2014. Ecological notes on seriema species in the Paraguayan Chaco, with observations on Chunga biology. Revista Brasileira de Ornitologia 22(2): 234-237.

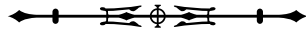


CARDOSO, S. R. T. \& S. M. A., SANTOS, 2012. Observações sobre predação da serpente Philodryas patagoniensis por aves. Biologia Geral e Experimental 12(2): 7-9. Disponível em: < https://www.researchgate. net/profile/Silvia_Travaglia-Cardoso/publication/284731997 Observacoes_sōbre_predacao_da_serpente_Philodryas_-

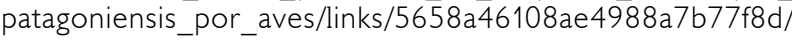
Observacoes-sobre-predacao-da-serpente-Philodryas-patagoniensispor-aves.pdf>. Acesso em: 11 julho 2016.

FOLLY, H., M. O. NEVES, E. A. PEREIRA, P. HOTEL, R. A. SOUZA \& D. J. SANTANA, 2015. Predation on Leposternon microcephalum Wagler, 1824 (Squamata, Amphisbaenidae) by Cariama cristata Linnaeus,1766 (Cariamiformes, Cariamidae). Herpetology Notes 8: $465-466$

GONZAGA, L. P. \& G. M. KIRWAN, 2017. Red-legged seriema (Cariama cristata). In: J. DEL HOYO, A. ELLIOT, J. SARGATAL, D. A. CHRISTIE \& E. DE JUANA (Ed.): Handbook of the birds of the world alive. Lynx Edicions, Barcelona. Disponível em: < http://www. hbw.com./node/53710>. Acesso em: 15 junho 2017.
HALLAGER, S., 2013. North American Studbook for the redlegged seriema: 1-84. Smithsonian's National Zoological Park, Washington.

MIRANDA, J. P., J. C. L. COSTA, F. M. SCARPA \& C. F. D. ROCHA, 2013. Predation on Columbina squammata (Aves: Columbidae) by the Green Vine Snake Oxybelis fulgidus (Serpentes: Colubridae) at the Lençóis Maranhenses National Park, Maranhão. Brazil Herpetology Notes 6: 187-188.

SICK, H., 1997. Ornitologia brasileira: 2 ed.: 1-912. Nova Fronteira, Rio de Janeiro.

SILVA, A. N., R. NUNES, D. C. ESTRELA, G. MALAFAIA \& A. L. S. CASTRO, 2016. Behavioral repertoire of the poorly known Red-legged Seriema, Cariama cristata (Cariamiformes: Cariamidae). Revista Brasileira de Ornitologia 24(2): 73-79.

WIKIAVES, 2017. Fogo-apagou. Disponível em: <wikiaves.com. br/fogo-apagou>. Acesso em: 15 junho 2017. 